\title{
Comparing the accuracy of ES-BC, EIS-GS, and ES Oxi on body composition, autonomic nervous system activity, and cardiac output to standardized assessments
}

\author{
This article was published in the following Dove Press journal: \\ Medical Devices: Evidence and Research \\ 15 September 2011 \\ Number of times this article has been viewed
}

\author{
John E Lewis' \\ Stacey L Tannenbaum' \\ Jinrun $\mathrm{Gao}^{3}$ \\ Angelica B Melillo' \\ Evan G Long' \\ Yaima Alonso ${ }^{2}$ \\ Janet Konefal' \\ Judi MWoolger ${ }^{2}$ \\ Susanna Leonard' \\ Prabjot K Singh' \\ Lawrence Chen' \\ Eduard Tiozzo' \\ 'Department of Psychiatry and \\ Behavioral Sciences, ${ }^{2}$ Department of \\ Medicine, University of Miami Miller \\ School of Medicine, Miami, FL, ${ }^{3}$ State \\ Farm Insurance, Bloomington, IL, USA
}

Correspondence: John E Lewis University of Miami Miller School of Medicine, Department of Psychiatry and Behavioral Sciences, I I 20 NW I4th Street, Suite \#|474 (D2I),

Miami, FL 33।36, USA

Tel +l 3052436227

Fax + I 3052433648

Email jelewis@miami.edu
Background and purpose: The Electro Sensor Complex (ESC) is software that combines three devices using bioelectrical impedance, galvanic skin response, and spectrophotometry: (1) ES-BC (Electro Sensor-Body Composition; LD Technology, Miami, FL) to assess body composition, (2) EIS-GS (Electro Interstitial Scan-Galvanic Skin; LD Technology) to predict autonomic nervous system activity, and (3) ES Oxi (Electro Sensor Oxi; LD Technology) to assess cardiac output. The objective of this study was to compare each to a standardized assessment: ES-BC to dual-energy X-ray absorptiometry (DXA), EIS-GS to heart rate variability, and ES Oxi to BioZ Dx Diagnostic System (BioZ Dx; SonoSite Inc, Bothell, WA).

Patients and methods: The study was conducted in two waves. Fifty subjects were assessed for body composition and autonomic nervous system activity. Fifty-one subjects were assessed for cardiac output.

Results: We found adequate relative and absolute agreement between ES-BC and DXA for fat mass $(r=0.97, P<0.001)$ with ES-BC overestimating fat mass by $0.1 \mathrm{~kg}$ and for body fat percentage $(r=0.92, P<0.001)$ with overestimation of fat percentage by $0.4 \%$. For autonomic nervous system activity, we found marginal relative agreement between EIS-GS and heart rate variability by using EIS-GS as the predictor in a linear regression equation (adjusted $R^{2}=0.56$, $P=0.03$ ). For cardiac output, adequate relative and absolute agreement was found between ES Oxi and BioZ Dx at baseline $(r=0.60, P<0.001)$, after the first exercise stage $(r=0.79$, $P<0.001)$, and after the second exercise stage $(r=0.86, P<0.001)$. Absolute agreement was found at baseline and after both bouts of exercise; ES Oxi overestimated baseline and stage 1 exercise cardiac output by $0.3 \mathrm{~L} /$ minute and $0.1 \mathrm{~L} /$ minute, respectively, but exactly estimated stage 2 exercise cardiac output.

Conclusion: ES-BC and ES Oxi accurately assessed body composition and cardiac output compared to standardized instruments, whereas EIS-GS showed marginal predictive ability for autonomic nervous system activity. The ESC software managing the three devices would be useful to help detect complications related to metabolic syndrome, diabetes, and cardiovascular disease and to noninvasively and rapidly manage treatment follow-up.

Keywords: fat mass, autonomic nervous system activity, Electro Sensor Complex, dual-energy $\mathrm{X}$-ray absorptiometry, heart rate variability, and bioimpedance cardiography

\section{Introduction}

During the past twenty years, the US has succumbed to a pervasive obesity epidemic. ${ }^{1,2}$ In 1980, fewer than $47 \%$ of Americans were overweight (body mass index [BMI] $\left.>25 \mathrm{~kg} / \mathrm{m}^{2}\right)$ and less than $15 \%$ were obese $\left(\mathrm{BMI}>30 \mathrm{~kg} / \mathrm{m}^{2}\right)$. Today, approximately 
$67 \%$ of Americans are overweight and over $27 \%$ are obese. ${ }^{2,3}$ Unfortunately, a concurrent and parallel rise in metabolic syndrome exists and is accompanied by complications of diabetes, hypertension, and cardiovascular disease (CVD). The prevalence of metabolic syndrome appears to be roughly $33 \%$ of the American population according to standard guidelines. ${ }^{4,5}$

An interaction of factors contributes to the complications of metabolic syndrome on multiple organ system levels. For example, central fat is linked to increased inflammation, risk of diabetes, and metabolic syndrome. ${ }^{6-8}$ Autonomic nervous system imbalance, including vasoconstriction, increases heart rate and levels of epinephrine and norepinephrine, and hemodynamic disorders (eg, systemic vascular resistance or cardiac output deficits) are also pathological factors leading to hypertension, diabetes, and CVD. ${ }^{9,10}$

A software complex (Electro Sensor Complex [ESC]) managing three devices, ES-BC (Electro Sensor-Body Composition; LD Technology, Miami, FL), EIS-GS (Electro Interstitial Scan-Galvanic Skin; LD Technology), and ES Oxi (Electro Sensor Oxi; LD Technology), can rapidly measure all of the aforementioned factors related to metabolic syndrome: (1) body composition, (2) autonomic nervous system activity, and (3) cardiac output, respectively. The ES-BC device uses bioelectrical impedance analysis to estimate percent body fat, but it has never been compared to a gold standard for body composition, such as dual-energy X-ray absorptiometry (DXA). ${ }^{11}$ The EIS-GS response device has been shown to reflect autonomic nervous system activity, however it has never been used to predict a standardized assessment, such as heart rate variability (HRV). ${ }^{12}$ The ES Oxi device, using a digital pulse oximeter with photoelectric plethysmography, can estimate arterial stiffness, ${ }^{13}$ but it has never been compared to a standardized assessment of cardiac output, such as with the BioZ Dx Diagnostic System (BioZ Dx; SonoSite Inc, Bothell, WA) that uses impedance cardiography. Thus, if the assessments from the three devices (ES-BC, EIS-GS, and ES Oxi) are not different when compared to standardized assessments, then the ESC software would be particularly useful for detecting complications related to metabolic syndrome, diabetes, and CVD and to potentially assist in managing treatment follow-up. In addition, the ESC software managing the three devices can assess patients within 5 minutes, providing a rapid and convenient clinical tool.

Given the enormous public health burden of metabolic syndrome and the associated morbidities of diabetes, hypertension, and CVD, an accurate, easy-to-use, low-cost, and rapid assessment of body composition, autonomic nervous system activity, and cardiac output would greatly improve the assessment and treatment of at-risk individuals, especially if it was performed by trained nonclinical personnel, ie, individuals assisting physicians. Therefore, the objectives of this study were to compare the: (1) ES-BC to DXA, the gold standard of body composition assessment; (2) EIS-GS response device to a standardized assessment of autonomic nervous system activity (ie, HRV); and (3) ES Oxi device to a standardized assessment of cardiac output (BioZ Dx). The results of the study will be applicable for clinicians interested in simplifying the screening and management plan of metabolic syndrome, diabetes, hypertension, and CVD.

\section{Materials and methods}

This study was performed in two waves; the first to assess body composition and autonomic nervous system activity and the second to assess cardiac output. Both waves of the study were conducted with the approval of the University of Miami Institutional Review Board for human subjects' research, participants signed informed consent before commencing in the study, and confidentiality was maintained for all participants' data.

\section{Wave I}

\section{Study participants}

All participants $(n=50)$ were recruited by referrals at the University of Miami Miller School of Medicine campus throughout 2009. The sample comprised of $40 \%$ males $(n=20)$ and $60 \%$ females $(n=30)$ with a mean age of 32.3 years (standard deviation $[\mathrm{SD}]=10.2$; range 20-62).

\section{Inclusion and exclusion criteria}

Potential participants were $\geq 18$ years of age and had expressed an interest in having their body composition and autonomic nervous system activity assessed. Subjects were not enrolled in the study if they: (1) were unable to consent to the study; (2) wore an automatic external defibrillator device; (3) had erratic, accelerated, or mechanically-controlled irregular heart rhythms; (4) had arterial fibrillation/flutter; (5) had atrioventricular block; (6) had dermatological lesions or excessive hair that would be in contact with the placement of the electrodes on the devices; (7) had any implanted electronic device; (8) were during or within \pm 2 days of menstruation; (9) had a fever above $37^{\circ} \mathrm{C}$ during the assessment; (10) were taking diuretics; (11) had a history of renal or heart failure; (12) had excessively used alcohol or stimulants (amphetamines) 12 hours before the examination; (13) had diarrhea during the assessment; (14) had engaged in intense physical activity or the use of a sauna 
8 hours before the examination; (15) had edema; and/or (16) were pregnant.

\section{Procedure}

Each participant completed a basic demographics and medical history questionnaire on the day of the assessment. Height, to the nearest $0.5 \mathrm{~cm}$, and weight, to the nearest $0.5 \mathrm{~kg}$, were measured with a standard scale. Subjects were assessed with the ES-BC and EIS-GS, including HRV, at the University of Miami Center for Complementary and Integrative Medicine and then taken to the Pediatric Clinical Research Laboratory for the DXA scan. The entire assessment took less than 1 hour for each participant.

\section{Body composition: ES-BC assessment}

ES-BC uses a single frequency electrical bioimpedance analyzer in tetrapolar mode to assess body fat percentage and fat mass. The device measures current, voltage, and phase angle and calculates impedance, resistance, and reactance. The software computes these values using accepted peerreviewed published algorithms tailored to the general population and persons who are obese. ${ }^{14-17}$ The software automatically selects the algorithm based on the participant's values entered into the database (ie, gender, height, weight, age, and activity level). ${ }^{16}$

\section{Body composition: DXA assessment}

DXA was conducted with a Lunar Prodigy Pro $^{\mathrm{TM}}$ scanner with enCORE software 7.5 (GE Healthcare, Madison, WI), which has previously demonstrated adequate reliability for body composition assessment. ${ }^{18}$ DXA is based on the three-compartment model of body composition and uses dual-energy X-ray to measure fat, lean soft tissue, and bone mineral in approximately 10 minutes. ${ }^{11}$

\section{Autonomic nervous system activity: EIS-GS assessment}

The EIS-GS utilizes a universal serial bus (USB) plug and play hardware including an interface box, disposable electrodes, and reusable plates and cables with software installed on a computer. The system performs bioimpedance in bipolar mode with direct current and measures the electrical conductivity of 11 pathways of the body, each recorded twice from anode to cathode $(\mathrm{SDC}+)$ and then from cathode to anode (SDC-). Electrode polarization does not affect the bioimpedance measurement, ${ }^{19}$ and the transmission of the current from the electrode to the hardware is performed by chronoamperometry. ${ }^{20}$ With direct current, the plasma membrane acts as an insulator, and the current is not able to penetrate the cell, so most of the current flows around the cell and remains in the interstitial fluid. ${ }^{19}$ Analysis of the direct current in electrolytic solution is performed at both the anode and the cathode. The electrochemical reaction at the cathode is: $2 \mathrm{H}_{2} \mathrm{O}+2^{\mathrm{e}-}=\mathrm{H}_{2}$ (gas) $+2 \mathrm{OH}$-(base), and the electrochemical reaction for water at the anode is: $2 \mathrm{H}_{2} \mathrm{O}=\mathrm{O}_{2}$ (gas) $+4 \mathrm{H}^{+}+4^{\mathrm{e}-}$ (acid). Finally, spectral analysis by EIS-GS is an application of the fast Fourier transform of the entire signal composed of the conductivity measurements. The fast Fourier transform components of EIS-GS are high frequency (HF), low frequency (LF), and very low frequency (VLF).

\section{Autonomic nervous system activity: HRV analysis}

Standardized assessment of the autonomic nervous system involves electrocardiogram rhythm analysis of the $\mathrm{NN}$ and RR intervals both in the full domain of activity and in the spectral analysis. ${ }^{21}$ The HRV assessment records three main spectral components in 2-5 minutes: VLF, LF, and HF. ${ }^{22}$ The HF percent represents parasympathetic (vagal) activity, and the LF percent represents sympathetic system activity. ${ }^{21,22}$

\section{Wave 2}

\section{Study participants}

All participants $(n=51)$ were recruited by referrals at the University of Miami Miller School of Medicine campus throughout 2010. The sample was comprised of $49 \%$ males $(\mathrm{n}=25)$ and $51 \%$ females $(\mathrm{n}=26)$ with a mean age of 31.1 years $(\mathrm{SD}=10.8$; range $18-65)$.

\section{Inclusion and exclusion criteria}

In addition to the same inclusion/exclusion criteria as those in wave 1, potential participants for wave 2 could not have: (1) had dyes recently introduced into the bloodstream, such as methylene blue, indocyanine green, indigo carmine, and fluorescein; (2) had significant levels of dysfunctional hemoglobins, such as carboxyhemoglobin or methemoglobin; (3) had any condition restricting blood flow, such as severe systemic vascular resistance; and/or (4) worn fingernail polish or false fingernails during the testing. Any of these could affect the accuracy of peripheral oxygen saturation of arterial hemoglobin $\left(\mathrm{SpO}_{2} \%\right)$ measurement from the oximeter, so subjects meeting any of these criteria were excluded.

\section{Procedure}

Each participant completed a basic demographics and medical history questionnaire at the assessment. Subjects were assessed with ES Oxi and BioZ Dx devices in the University of Miami Center for Complementary and Integrative 
Medicine and Medical Wellness Center. Each subject began the assessment by sitting at rest for 5 minutes and had cardiac output measured simultaneously by ES Oxi and BioZ Dx devices. Then, the subject walked for 6 minutes on a treadmill at low-to-moderate intensity (less than $70 \%$ of maximal ageadjusted predicted heart rate [220-age]), and cardiac output was measured simultaneously immediately afterward by ES Oxi and BioZ Dx devices. Finally, each subject walked for a second 6-minute bout of exercise on the treadmill at the same intensity, and cardiac output was measured simultaneously immediately afterward by ES Oxi and BioZ Dx devices. Thus, three measurements were completed: one at rest and two following 6-minute bouts of low-to-moderate intensity exercise on a treadmill. The entire assessment took less than 1 hour for each participant.

\section{Cardiac output: ES Oxi}

The ES Oxi module utilizes a USB plug and play hardware device including an electronic box and reusable $\mathrm{SpO}_{2}$ probe and software installed on a computer. It is intended to: (1) spot check or monitor $\mathrm{SpO}_{2} \%$ and pulse rate and (2) analyze the pulse waveform (photoelectrical plethysmography) provided by the oximeter. The analysis provides indicators of arterial stiffness. ${ }^{23}$ The ES Oxi uses the same algorithms as BioZ Dx to derive mean arterial pressure, systemic vascular resistance, and stroke volume. ${ }^{24}$

\section{Cardiac output: BioZ Dx impedance cardiography assessment}

BioZ Dx is a noninvasive heart monitor based on technology known as impedance cardiography. BioZ Dx provides the clinician with information about the heart's ability to deliver blood to the body, the amount of force the heart exerts at each beat, and the amount of fluid in the chest. Speciallydesigned bioimpedance sensors placed on the neck and chest monitor 12 different parameters, including cardiac output, contractility, systemic vascular resistance, and thoracic fluid content. These sensors monitor the electrical conductivity of the thoracic part of the body. ${ }^{24}$

\section{Data analysis for study waves I and 2}

Data were analyzed using SPSS for Windows (v 18; SPSS Inc, Chicago, IL). Frequency and descriptive statistics were calculated on all variables. We used chi-square to compare subjects by body fat percentage categories on the ES-BC and DXA assessments according to criteria of the American Council on Exercise for women and men. For women, essential fat is $10 \%-13 \%$, athlete is $14 \%-20 \%$, fitness is
$21 \%-24 \%$, average is $25 \%-31 \%$, and obesity is $32 \%$ or greater. For men, essential fat is $2 \%-5 \%$, athlete is $6 \%-13 \%$, fitness is $14 \%-17 \%$, average is $18 \%-24 \%$, and obesity is $25 \%$ or greater. We used independent sample $t$-tests to compare differences between ES-BC and DXA for body fat percentage and fat mass and ES Oxi and BioZ Dx for cardiac output. We used Pearson product-moment correlation to determine the strength of the relationships between: (1) ES-BC and DXA for body fat percentage and fat mass and (2) ES Oxi and BioZ Dx at baseline and after both bouts of exercise for cardiac output. To evaluate the presence of systematic error between each pair of variables, Pearson product-moment correlation was utilized to compare the average of the methods and the mean difference score for each method. Bland-Altman analysis was used to determine absolute limits of agreement for each variable. ${ }^{25,26}$ For autonomic nervous system activity, we used linear regression to determine the predictability of EIS-GS HF (normal range $22 \%-34 \%$ ) on HRV LF (normal range $22 \%-46 \%$ ). We evaluated the adjusted $\mathrm{R}^{2}$ of the model and the $95 \%$ confidence intervals of the intercept and slope to assess the level of systematic error between the two variables. We used $\alpha=0.05$ as the criterion for statistical significance.

\section{Results}

Overall, subjects completed the assessments without reporting any adverse events, and the assessments were completed in a timely fashion.

\section{Clinical measurements}

For wave 1 , the participants' $(n=50)$ mean height was $169.5 \mathrm{~cm}(\mathrm{SD}=11.0$, range 150-190.5), mean weight was $72.0 \mathrm{~kg}(\mathrm{SD}=19.0$, range $45-117)$, and mean BMI was $25.1 \mathrm{~kg} / \mathrm{m}^{2}(\mathrm{SD}=6.2$, range $18.4-48.7)$. For wave 2 , the participants' $(\mathrm{n}=51)$ mean height was $172.0 \mathrm{~cm}(\mathrm{SD}=11.0$, range 152-193), mean weight was $78.5 \mathrm{~kg}(\mathrm{SD}=19.0$, range 54-136), and mean BMI was $26.4 \mathrm{~kg} / \mathrm{m}^{2}(\mathrm{SD}=6.6$, range 19.6-56.7).

\section{Body composition}

The chi-square analysis between ES-BC and DXA resulted in a disparate proportion of classifications $\left(\chi^{2}[9]=46.3\right.$, $P<0.001)$. According to ES-BC body fat percentage, subjects were classified as: $(1)$ athlete $(n=4,8 \%)$, fitness $(\mathrm{n}=9,18 \%)$, average $(\mathrm{n}=20,40 \%)$, and obese $(\mathrm{n}=17$, $34 \%$ ). According to DXA body fat percentage, subjects were classified as: $(1)$ athlete $(n=8,16 \%)$, fitness $(n=11,22 \%)$, average $(n=15,30 \%)$, and obese $(n=16,32 \%)$. For example, 
DXA classified eight subjects in the athlete category, whereas ES-BC only classified four subjects in the athlete category, and only two subjects were classified as an athlete according to both devices.

The mean values according to ES-BC for body fat percentage and fat mass were statistically similar to DXA. We found adequate relative agreement between ES-BC and DXA, as the correlation values of these two methods for fat mass was $r=0.97, P<0.001$ and for body fat percentage was $r=0.92, P<0.001$. Compared to DXA in absolute terms, ES-BC overestimated fat mass by $0.1 \mathrm{~kg}$ and body fat percentage by $0.4 \%$ with wide limits of agreement for each variable (fat mass -7.0 to $7.2 \mathrm{~kg}$ and body fat percentage $-8.8 \%$ to $9.5 \%$ ) (Table 1 , Figures 1 and 2 ). For fat mass, systematic error was observed between ES-BC and DXA, as indicated by a significant correlation of the difference value and the average score $(r=0.60, P<0.001)$. Systematic error was also observed for body fat percentage with a significant correlation found between the difference value and the average score $(r=0.61, P<0.001)$. At higher levels of fat mass and body fat percentage, ES-BC underestimated both values compared to DXA.

\section{Autonomic nervous system activity}

Utilizing EIS-GS HF as the predictor variable and the HRV LF as the dependent variable in a linear regression, the model was statistically significant $(\mathrm{F}[1,49]=63.8, P<0.001)$. The

Table I Comparisons between devices on body composition, autonomic nervous system activity, and cardiac output

\begin{tabular}{|c|c|c|c|}
\hline \multicolumn{3}{|l|}{ Measure } & \multirow{2}{*}{$\begin{array}{l}t \text {-test }(\mathrm{df}) \\
P \text { value } \\
\end{array}$} \\
\hline & ES-BC & DXA & \\
\hline Fat mass $(\mathrm{kg})$ & $\begin{array}{l}19.8 \pm 10.2 \\
(10.6,58.2)\end{array}$ & $\begin{array}{l}19.7 \pm 12.3 \\
(6.7,60.5)\end{array}$ & $\begin{array}{l}0.04(98) \\
0.97\end{array}$ \\
\hline Body fat percentage & $\begin{array}{l}26.8 \pm 8.2 \\
(12.2,50.5)\end{array}$ & $\begin{array}{l}26.5 \pm 11.0 \\
(8.6,53.5)\end{array}$ & $\begin{array}{l}0.18(98) \\
0.86\end{array}$ \\
\hline & EIS-GS & HRV & \\
\hline \multirow[t]{2}{*}{$\begin{array}{l}\text { Autonomic nervous system } \\
\text { activity (frequency) }\end{array}$} & $\begin{array}{l}24.6 \pm 8.8 \\
(2.7,49.7)\end{array}$ & $\begin{array}{l}33.5 \pm 12.1 \\
(15.3,62.4)\end{array}$ & $\begin{array}{l}4.17(98) \\
0.0001\end{array}$ \\
\hline & ES Oxi & BioZ Dx & \\
\hline $\begin{array}{l}\text { Baseline resting cardiac } \\
\text { output (L/minute) }\end{array}$ & $\begin{array}{l}6.1 \pm 1.1 \\
(4.0,10.0)\end{array}$ & $\begin{array}{l}5.8 \pm 1.3 \\
(3.7,8.9)\end{array}$ & $\begin{array}{l}1.26(100) \\
0.21\end{array}$ \\
\hline $\begin{array}{l}\text { First exercise stage } \\
\text { cardiac output (L/minute) }\end{array}$ & $\begin{array}{l}6.1 \pm 1.0 \\
(4.5,8.8)\end{array}$ & $\begin{array}{l}6.0 \pm 1.3 \\
(2.6,8.6)\end{array}$ & $\begin{array}{l}0.44(100) \\
0.66\end{array}$ \\
\hline $\begin{array}{l}\text { Second exercise stage cardiac } \\
\text { output (L/minute) }\end{array}$ & $\begin{array}{l}6.2 \pm 1.2 \\
(4.0,8.8)\end{array}$ & $\begin{array}{l}6.2 \pm 1.4 \\
(3.8,9.2)\end{array}$ & $\begin{array}{l}0.01(100) \\
0.99\end{array}$ \\
\hline
\end{tabular}

Note: Values are mean \pm standard deviation (minimum, maximum).

Abbreviations: ES-BC, Electro Sensor-Body Composition; EIS-GS, Electro Interstitial Scan-Galvanic Skin; ES Oxi, Electro Sensor Oxi; DXA, dual-energy X-ray absorptiometry; HRV, heart rate variability; BioZ Dx, BioZ Dx Diagnostic System; $\mathrm{df}$, degrees of freedom. adjusted $\mathrm{R}^{2}$ value was 0.56 . The $95 \%$ confidence interval of the intercept was 1.02 and 14.7 (intercept does not include 0 ), and the $95 \%$ confidence interval of the slope was 0.78 and 1.30 (slope does include 1), thus demonstrating some level of systematic error.

\section{Cardiac output}

Adequate relative agreement was found between ES Oxi and BioZ Dx based on strong correlation values of $r=0.60$, $P<0.001$ at baseline, $r=0.79, P<0.001$ after the first exercise stage, and $r=0.86, P<0.001$ after the second exercise stage. The mean cardiac output values according to ES Oxi for baseline, stage 1 exercise, and stage 2 exercise were statistically similar to BioZ Dx. Compared with BioZ Dx in absolute terms, ES Oxi overestimated baseline and stage 1 exercise cardiac output by $0.3 \mathrm{~L} /$ minute and $0.1 \mathrm{~L} /$ minute, respectively, but exactly estimated stage 2 exercise cardiac output with narrow limits of agreement for each variable (baseline cardiac output -1.9 to $2.4 \mathrm{~L} /$ minute; stage 1 exercise cardiac output -1.5 to $1.6 \mathrm{~L} /$ minute; and stage 2 exercise cardiac output -1.3 to $1.4 \mathrm{~L} /$ minute) (Table 1, Figures 3-5). No systematic bias was demonstrated for baseline and stage 2 exercise cardiac output $(r=0.18, P=0.20$ and $r=0.28$, $P=0.05$, respectively). For stage 1 exercise cardiac output, systematic bias was observed between the two methods $(r=0.40, P<0.01)$.

\section{Discussion}

The results of the study demonstrate relative and absolute agreement of ES-BC, a measure of body composition, and ES Oxi, a measure of cardiac output, when compared with the standard assessments of DXA and BioZ Dx, respectively. For ES-BC, the limits of agreement were wide and systematic error was present. For ES Oxi, all three measures had narrow limits of agreement and systematic error was only present in stage 1 exercise, but not present for baseline or stage 2 exercise. Regarding autonomic nervous system activity, the results indicate marginal predictive ability of EIS-GS when regressed on HRV.

Given the enormous epidemics of metabolic syndrome and obesity, the ES-BC device makes it simple and easy for clinicians to provide their patients with information about body fat composition. Most clinicians do not have access to DXA equipment and are unfamiliar with administering a body fat assessment with a skinfold caliper. The ES-BC device provides the ability to accurately assess patients' body fat composition. The ES-BC assessment is potentially more accurate than assessing adiposity with BMI, as BMI is not a 


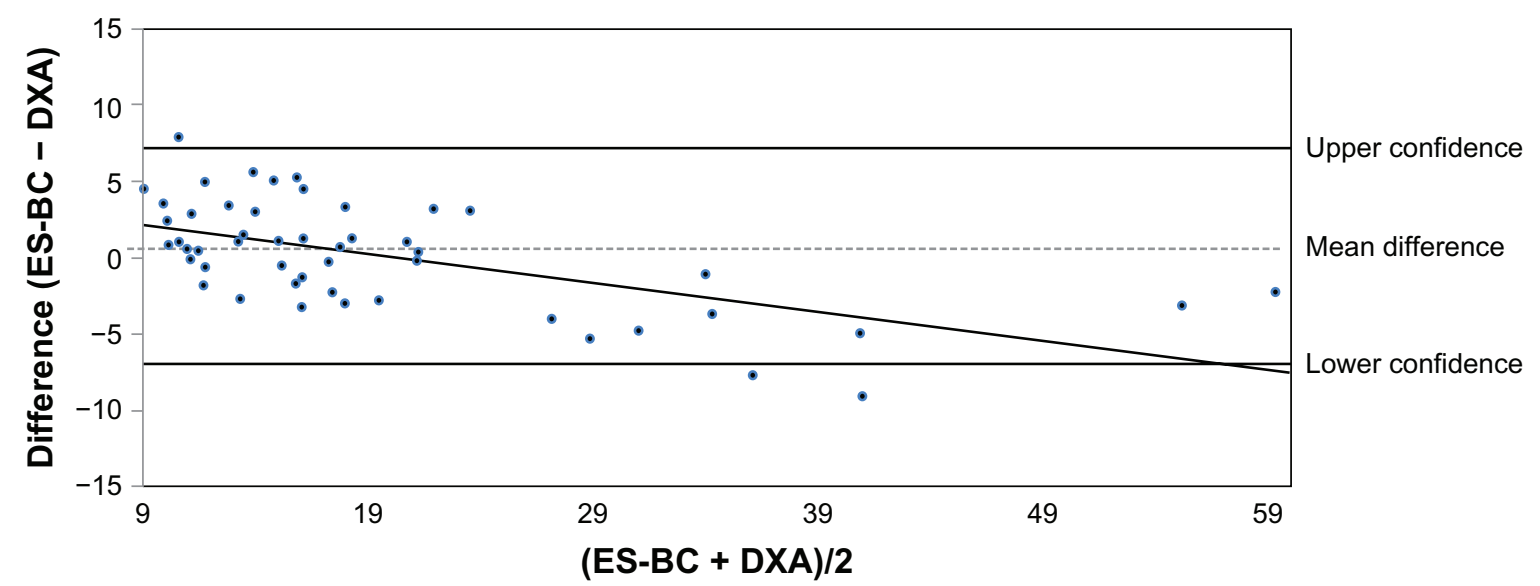

Figure I Bland-Altman plot of fat mass between ES-BC (Electro Sensor-Body Composition; LD Technology, Miami, FL) and dual-energy X-ray absorptiometry (DXA).

direct measure of body fat. ${ }^{27,28}$ The ES-BC assessment may also be more accurate than other bioimpedance devices that have been previously compared to DXA and demonstrated less significant relationships among body composition variables. $^{29}$

The marginal predictive capacity of EIS-GS on HRV raises a question about what EIS-GS is actually measuring. HRV is related to sympathetic system activity estimated at the level of the HRV, and EIS-GS is related to sympathetic system activity estimated at the level of the interstitial fluid. The interstitial fluid represents the main component of living tissue. The mechanisms of action of the autonomic nervous system activity on living tissue are: (1) vasoconstriction of capillaries to decrease tissue blood flow, ${ }^{30}$ (2) increased Na-K ATP pump activity, ${ }^{31}$ and (3) shifting capillary fluid to regulate blood pressure and increase the interstitial fluid volume..$^{32}$ Therefore, EIS-GS could be a marker of vasoconstriction and blood flow, Na-K ATP pump activity, and interstitial fluid volume.
Additional studies have been performed to further explicate these relationships, and EIS-GS has been used to screen for prostate cancer as an adjunct to prostate specific antigen $^{33}$ and as a marker of selective serotonin reuptake inhibitor treatment response. ${ }^{34}$ In these two studies, some conclusions were drawn to show that EIS-GS could detect prostate cancer and could be a marker of the response to selective serotonin reuptake inhibitor treatment through the electrochemical detection of acidic tissue or a change in the impedance in abnormal tissue. However, the detection of autonomic nervous system activity was not determined in these two studies.

Given the severity and magnitude of CVD as the number one global killer ${ }^{35}$ and hypertension as a major risk factor in the development of metabolic syndrome, ischemic heart disease, heart failure, kidney disease, and cerebrovascular disease leading to stroke, ${ }^{36}$ the ability to accurately measure the cardiac output with ES Oxi could prove to be invaluable. For example, because hypertension is a hemodynamic disorder,

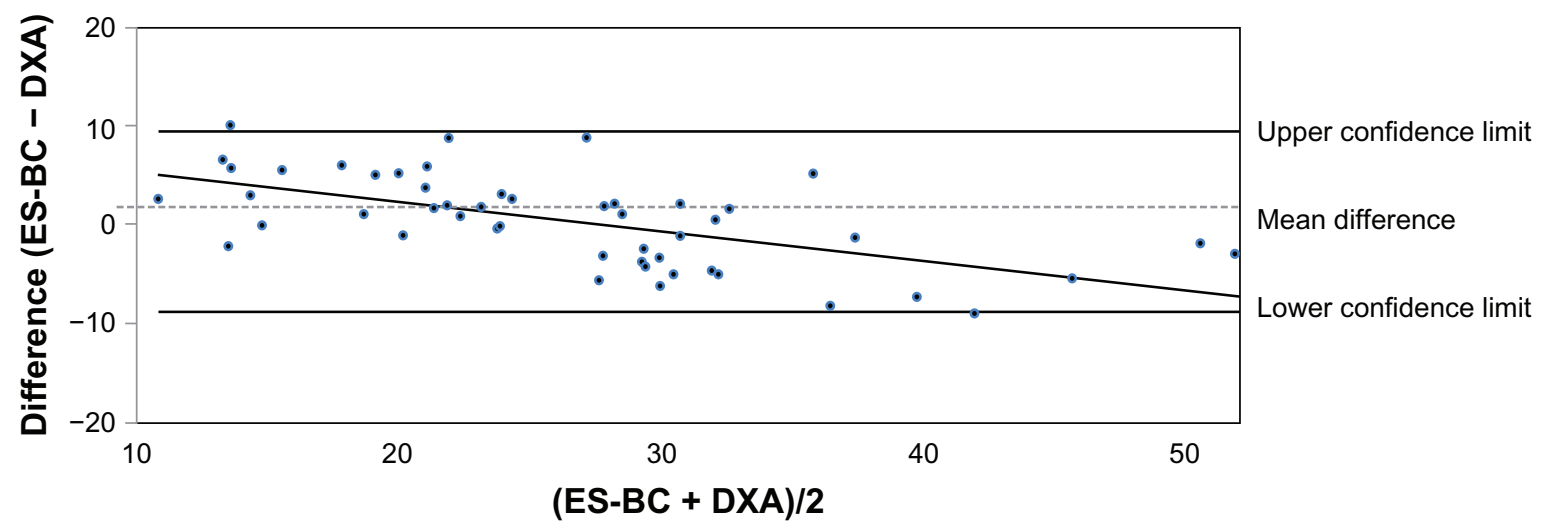

Figure 2 Bland-Altman plot of body fat percentage between ES-BC (Electro Sensor-Body Composition; LD Technology) and dual-energy X-ray absorptiometry (DXA). 


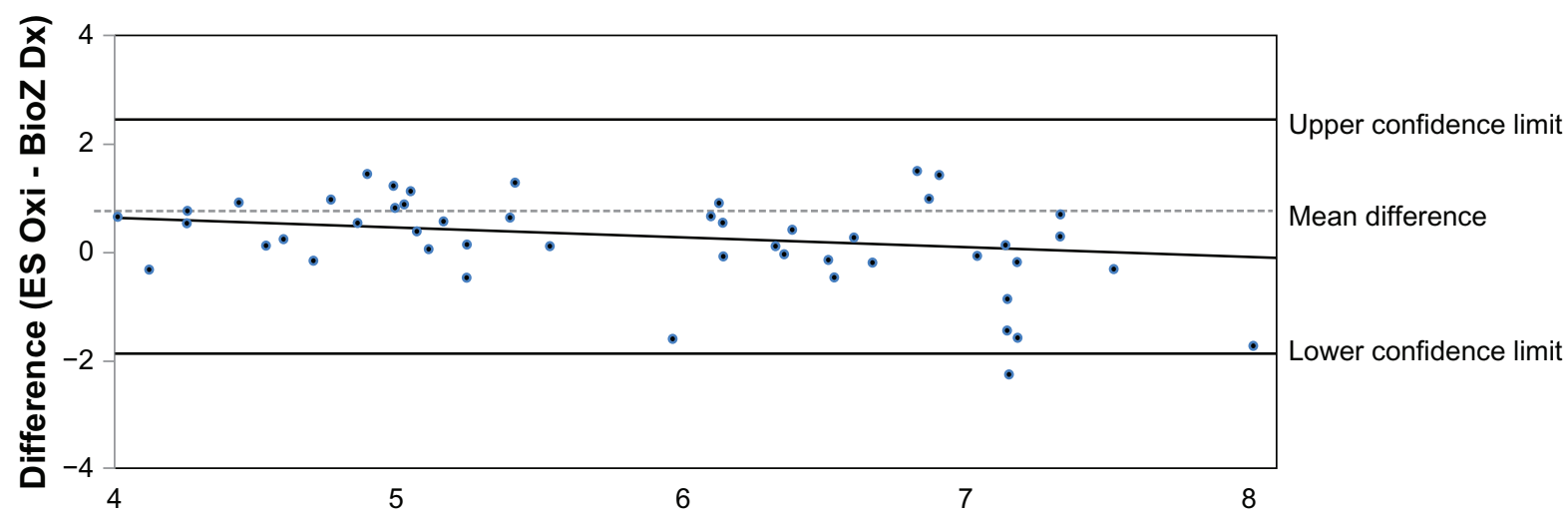

$(E S$ Oxi $+B i o Z D x) / 2$

Figure 3 Bland-Altman plot of baseline cardiac output between ES Oxi (Electro Sensor Oxi, LD Technology) and BioZ Dx Diagnostic System (BioZ Dx; SonoSite Inc, Bothell, WA).

measuring a patient's cardiac output before and after medical intervention may assist in the decision-making and evaluation of ongoing antihypertensive therapy, ${ }^{36,37}$ especially given that hypertension is only properly controlled in about one-third of all cases..$^{32}$ Different medication classes used in the management of hypertension make it challenging at best for the clinician to determine the optimal therapy for each patient, and physician perceptions and patient symptoms negatively affect the management and control of hypertension. . $^{38,39}$

Cardiac output, defined as the blood volume in liters ejected by the heart per minute, is regarded as the ultimate expression of cardiovascular performance. Resting cardiac output should be 4-8 L/minute to maintain normal tissue perfusion and normal delivery of oxygen and nutrients. Cardiac output values outside this range could be a sign of CVD, hypertension, stroke, or heart failure. Hence, regular cardiac output monitoring plays an essential role in the evaluation, treatment, and follow-up of CVD. Accordingly, a noninvasive, inexpensive, safe, and fast device that can assess cardiac output and other hemodynamic parameters would be a suitable alternative to other techniques that are invasive, expensive, and risky in patients with CVD.

Ideally, a technology that measures cardiac output should be noninvasive, accurate, and reliable. At present, no single device meets these criteria. Intermittent thermodilution is widely accepted as the clinical gold standard. This method requires the insertion of a pulmonary artery catheter to obtain one measurement every 3-4 minutes. ${ }^{40}$ However, this procedure is clearly too invasive for regular monitoring and general assessment of cardiac output. Two existing, less-invasive, and continuous methods are Esophageal Doppler monitoring and carbon dioxide re-breathing, but both of these require skilled operators and expensive measurement devices. ${ }^{40}$ Among the currently-used methods, impedance cardiography is probably the only noninvasive and automatic technique. However, the impedance device is big and expensive, and its accuracy is

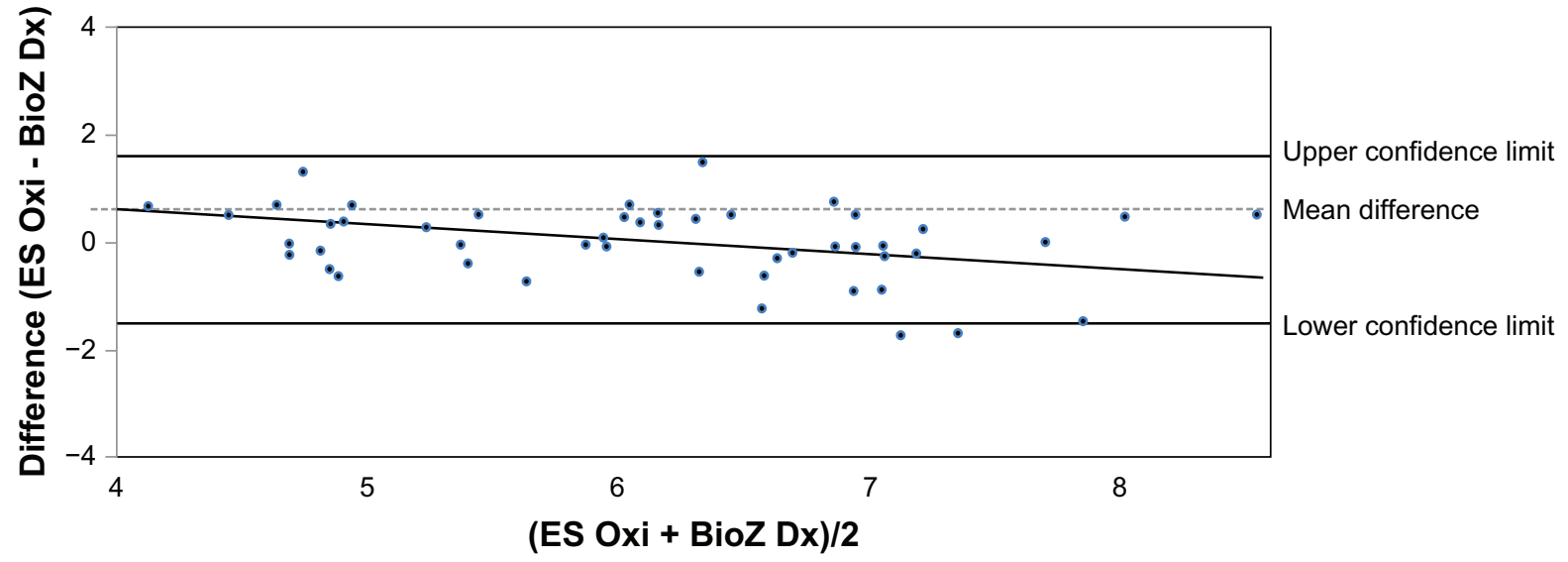

Figure 4 Bland-Altman plot of stage I exercise cardiac output between ES Oxi (Electro Sensor Oxi, LD Technology) and BioZ Dx Diagnostic System (BioZ Dx: SonoSite Inc). 


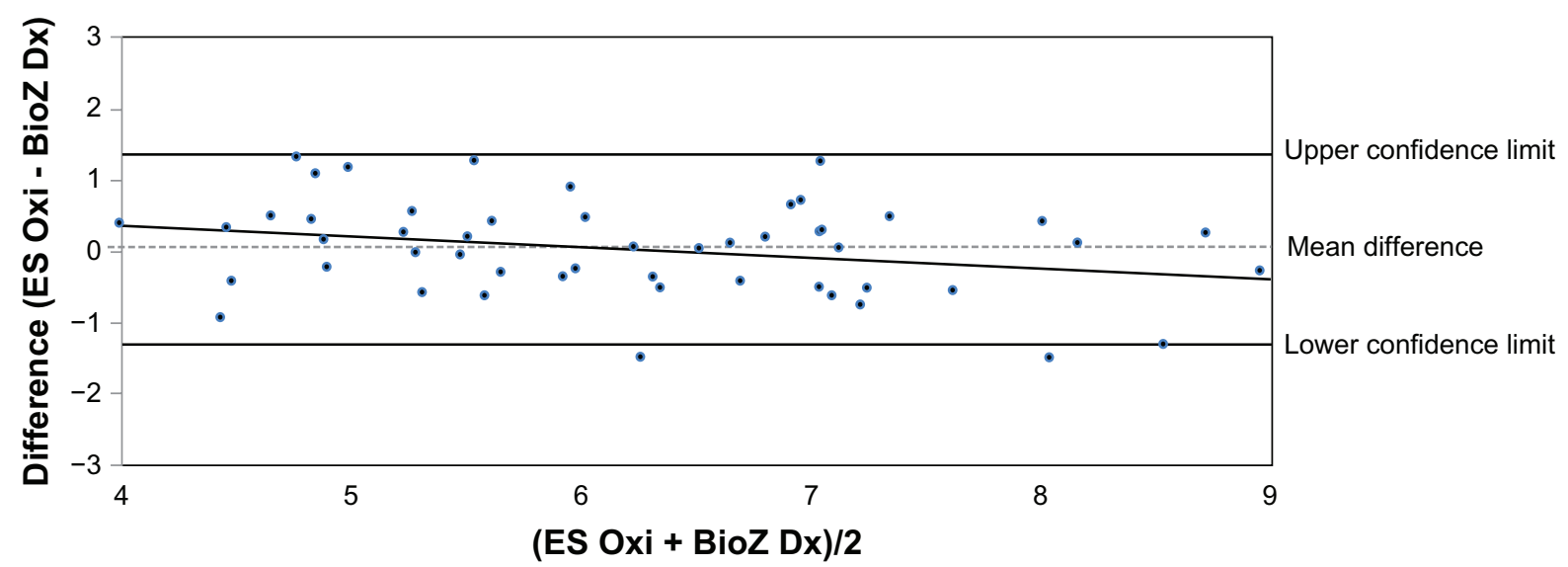

Figure 5 Bland-Altman plot of stage 2 exercise cardiac output between ES Oxi (Electro Sensor Oxi, LD Technology) and BioZ Dx Diagnostic System (BioZ Dx; SonoSite Inc).

often influenced by the change of electrode positions ${ }^{41}$ Due to these aforementioned disadvantages, these methods are all unquestionably limited to bedside use. They are not portable or wearable, making them difficult to incorporate into home health care monitoring systems. Thus, a digital pulse oximeter with photoelectric plethysmography, such as the ES Oxi device is a preferable method to assess cardiac output. ${ }^{42-44}$ The demonstrated relationship between ES Oxi and BioZ Dx on cardiac output combined with evaluating arterial stiffness, $\mathrm{SpO}_{2} \%$, and blood pressure could be useful for the practice management of metabolic syndrome, hypertension, and CVD for many physicians.

\section{Conclusion}

Given that many Americans are suffering from metabolic syndrome and the related maladies of CVD, hypertension, and diabetes, the ability to effectively manage these conditions with accuracy, speed, and reliability is necessary. A noninvasive and very low-risk device that can accurately and quickly portray a patient's current condition especially with an emphasis on body composition, autonomic nervous system activity, and cardiac output will enable the clinician to assist in planning initial and monitoring follow-up treatment. The ES-BC, EIS-GS, and ES Oxi devices managed with the ESC software demonstrated overall accuracy with a rapid assessment (measurements can be taken in 5 minutes) compared to accepted standard methods for body composition, autonomic nervous system activity, and cardiac output without reports of any adverse events. The results of the study suggest that ES-BC and ES Oxi demonstrate the ability to accurately assess body composition and cardiac output compared to standardized instruments, whereas EIS-GS showed marginal predictive ability for autonomic nervous system activity as measured by HRV and requires further testing. Thus, according to other studies, ${ }^{33,34}$ it seems that EIS-GS measurements are dependent on more than just autonomic nervous system activity.

\section{Disclosure}

The authors report no conflicts of interest in this work.

\section{References}

1. Lewis JE, Schneiderman N. Nutrition, physical activity, weight management, and health. Rev Colomb Psiquiatr. 2006;35(Suppl 1): $157 \mathrm{~S}-175 \mathrm{~S}$.

2. Flegal KM, Carroll MD, Ogden CL, Johnson CL. Prevalence and trends in obesity among US adults,1999-2000. JAMA. 2002;288(14): $1723-1727$.

3. Mokdad AH, Bowman BA, Ford ES, Vinicor F, Marks JS, Koplan JP. The continuing epidemics of obesity and diabetes in the United States. JAMA. 2001;286(10):1195-1200.

4. Ford ES, Giles WH, Dietz WH. Prevalence of the metabolic syndrome among US adults: findings from the third National Health and Nutrition Examination Survey. JAMA. 2002;287(3):356-359.

5. Ford ES. Prevalence of the metabolic syndrome defined by the International Diabetes Federation among adults in the US Diabetes Care. 2005;28(11):2745-2749.

6. Duman BS, Turkoglu C, Gunay D, Cagatay P, Demiroglu C, Buyukdevrim AS. The interrelationship between insulin secretion and action in type 2 diabetes mellitus with different degrees of obesity: evidence supporting central obesity. Diabetes Nutr Metab. 2003;16(4): 243-250.

7. Janssen I, Katzmarzyk PT, Ross R. Waist circumference and not body mass index explains obesity-related health risk. Am J Clin Nutr. 2004;79(3):379-384.

8. Romero-Corral A, Somers VK, Sierra-Johnson J, et al. Normal weight obesity: a risk factor for cardiometabolic dysregulation and cardiovascular mortality. Eur Heart J. 2010;31(6):737-746.

9. Carnethon MR, Prineas RJ, Temprosa M, Zhang ZM, Uwaifo G, Molitch ME. The association among autonomic nervous system function, incident diabetes, and intervention arm in the Diabetes Prevention Program. Diabetes Care. 2006;29(4):914-919.

10. Sanford T, Treister N, Peters C. Use of noninvasive hemodynamics in hypertension management. Am J Hypertens. 2005;18(2 Pt 2): 87S-91S.

11. Roche AF, Heymsfield SB, Lohman TG, editors. Human body composition. Champaign, IL: Human Kinetics; 1996. 
12. Macleod AF, Smith SA, Cowell T, Richardson PR, Sonksen PH. Non-cardiac autonomic tests in diabetes: use of the galvanic skin response. Diabet Med. 1991;8 Spec No:S67-S70.

13. Allen J. Photoplethysmography and its application in clinical physiological measurement. Physiol Meas. 2007;28(3):R1-R39.

14. Brodie D, Moscrip V, Hutcheon R. Body composition measurement: a review of hydrodensitometry, anthropometry, and impedance methods. Nutrition. 1998;14(3):296-310.

15. Chumlea WC, Guo SS, Kuczmarski RJ, et al. Body composition estimates from NHANES III bioelectrical impedance data. Int J Obes Relat Metab Disord. 2002;26(12):1596-1609.

16. Rigaud B, Morucci JP, Chauveau N. Bioelectrical impedance techniques in medicine. Part I: Bioimpedance measurement. Second section: impedance spectrometry. Crit Rev Biomed Eng. 1996;24(4-6):257-351.

17. Schoeller DA. Bioelectrical impedance analysis. What does it measure? Ann N Y Acad Sci. 2000;904:159-162.

18. Guo Y, Franks PW, Brookshire T, Antonio Tataranni P. The intraand inter-instrument reliability of DXA based on ex vivo soft tissue measurements. Obes Res. 2004;12(12):1925-1929.

19. Grimnes S, Martinsen ØG. Bioimpedance and bioelectricity basics. San Diego, CA: Academic Press; 2000.

20. Cottrell FG. Application to the Cottrell equation to chronoamperometry. Z Phys Chem. 1902;42:385.

21. Task Force of the European Society of Cardiology and the North American Society of Pacing and Electrophysiology. Heart rate variability. Standards of measurement, physiological interpretation, and clinical use. Eur Heart J. 1996;17(3):354-381.

22. Sayers BM. Analysis of heart rate variability. Ergonomics. 1973;16(1): 17-32.

23. Millasseau SC, Ritter JM, Takazawa K, Chowienczyk PJ. Contour analysis of the photoplethysmographic pulse measured at the finger. J Hypertens. 2006;24(8):1449-1456.

24. Woltjer HH, Bogaard HJ, de Vries PM. The technique of impedance cardiography. Eur Heart J. 1997;18(9):1396-1403.

25. Bland JM, Altman DG. Statistical methods for assessing agreement between two methods of clinical measurement. Lancet. 1986;1(8476):307-310.

26. Bland JM, Altman DG. Applying the right statistics: analyses of measurement studies. Ultrasound Obstet Gynecol. 2003;22(1):85-93.

27. Romero-Corral A, Lopez-Jimenez F, Sierra-Johnson J, Somers VK. Differentiating between body fat and lean mass-how should we measure obesity? Nat Clin Pract Endocrinol Metab. 2008;4(6):322-323.

28. Romero-Corral A, Somers VK, Sierra-Johnson J, et al. Accuracy of body mass index in diagnosing obesity in the adult general population. Int J Obes (Lond). 2008;32(6):959-966.

29. Pateyjohns IR, Brinkworth GD, Buckley JD, Noakes M, Clifton PM. Comparison of three bioelectrical impedance methods with DXA in overweight and obese men. Obesity (Silver Spring). 2006;14(11): 2064-2070.
30. Valensi P, Smagghue O, Paries J, Velayoudon P, Nguyen TN, Attali JR. Peripheral vasoconstrictor responses to sympathetic activation in diabetic patients: relationship with rheological disorders. Metabolism. 1997;46(3):235-241.

31. Bers DM, Despa S. Na/K-ATPase - an integral player in the adrenergic fight-or-flight response. Trends Cardiovasc Med. 2009;19(4):111-118.

32. Brown CM, Stemper B, Welsch G, Brys M, Axelrod FB, Hilz MJ. Orthostatic challenge reveals impaired vascular resistance control, but normal venous pooling and capillary filtration in familial dysautonomia. Clin Sci (Lond). 2003;104(2):163-169.

33. de Abreu DS. Bioimpedance and chronoamperometry as an adjunct to prostate-specific antigen screening for prostate cancer. Cancer Manag Res. 2011;3:109-116.

34. Alexeev VG, Kuznecova LV. Bioimpedance in monitoring of effects of selective serotonin reuptake inhibitor treatment. Psychol Res Behav Manag. 2011;4:81-86.

35. World Health Organization. Cardiovascular Diseases, 2008. Geneva: World Health Organization; 2008

36. Chobanian AV, Bakris GL, Black HR, et al. The Seventh Report of the Joint National Committee on Prevention, Detection, Evaluation, and Treatment of High Blood Pressure: the JNC 7 report. JAMA. 2003;289(19):2560-2572.

37. Lund-Johansen P. Hemodynamic effects of antihypertensive agents. In: Doyle AE, editor. Clinical pharmacology of antihypertensive drugs (handbook of hypertension, volume II). Amsterdam; the Netherlands: Elsevier; 1988;41-72.

38. Berlowitz DR, Ash AS, Hickey EC, et al. Inadequate management of blood pressure in a hypertensive population. $N$ Engl J Med. 1998;339(27):1957-1963.

39. Paramore LC, Halpern MT, Lapuerta P, et al. Impact of poorly controlled hypertension on healthcare resource utilization and cost. Am J Manag Care. 2001;7(4):389-398.

40. Mathews L, Singh RK. Cardiac output monitoring. Ann Card Anaesth. 2008;11(1):56-68.

41. Richard R, Lonsdorfer-Wolf E, Charloux A, et al. Non-invasive cardiac output evaluation during a maximal progressive exercise test, using a new impedance cardiograph device. Eur J Appl Physiol. 2001;85(3-4):202-207.

42. Chowienczyk PJ, Kelly RP, MacCallum H, et al. Photoplethysmographic assessment of pulse wave reflection: blunted response to endotheliumdependent beta2-adrenergic vasodilation in type II diabetes mellitus. J Am Coll Cardiol. 1999;34(7):2007-2014.

43. McCombie D, Asada H, Reisner A. Identification of vascular dynamics and estimation of the cardiac output waveform from wearable PPG sensors. Conf Proc IEEE Eng Med Biol Soc. 2005;4:3490-3493.

44. Wang L, Zhang YT. A novel photoplethysmogram index for total peripheral resistance after bicycle exercise. In: Proceedings of the 5 th International Conference on Ubiquitous. Healthcare; 2008 Oct 29-31; Busan, Korea.
Medical Devices: Evidence and Research

\section{Publish your work in this journal}

Medical Devices: Evidence and Research is an international, peerreviewed, open access journal that focuses on the evidence, technology, research, and expert opinion supporting the use and application of medical devices in the diagnosis, treatment and management of clinical conditions and physiological processes. The identification of novel

\section{Dovepress}

devices and optimal use of existing devices which will lead to improved clinical outcomes and more effective patient management and safety is a key feature. The manuscript management system is completely online and includes a quick and fair peer-review system. Visit http://www. dovepress.com/testimonials.php to read real quotes from authors. 